\title{
Multidisciplinary Management of Anterior Traumatized Tooth: A Case Report
}

\author{
Emi George ${ }^{1}$, Radhakrishnan Nair K², Praveena Geetha ${ }^{3}$, Rakhi P Veedu ${ }^{4}$, Merin Joseph ${ }^{5}$
}

\begin{abstract}
Background: Traumatized anterior teeth with subgingival crown-root fractures are a challenge to treat. Treatment of crown-root fractures often requires a multidisciplinary approach. Gingivectomy of the affected tooth can violate gingival contour of the tooth so orthodontic extrusion is a conservative procedure that allows extrusion of a tooth without any bone loss.

Case description: This case report details the multidisciplinary management of the traumatized anterior tooth including endodontic treatment, orthodontic extrusion, and post-core-crown procedure to restore a right maxillary central incisor to achieve a satisfactory cosmetic result. The fractured fragment was removed and pulp tissue extirpation was done in 11. Obturation was completed at next appointment. The fracture line was extended subgingivally, so orthodontic extrusion was planned. After 8 weeks, the tooth had extruded around $2 \mathrm{~mm}$ of palatal tooth structure sufficient to provide a ferrule of $1 \mathrm{~mm}$. A cast post and core was prepared, and a definitive metal-ceramic crown was placed over 11 . The patient was reviewed for 6 months and 1 year.

Conclusion: Management of cervical third fracture has various treatment options. Orthodontic extrusion is a conservative procedure that allows retention of a tooth without any bone loss. Cast post and core can adapt to the canal and strengthen the tooth. It can be considered as a conservative treatment option.
\end{abstract}

Keywords: Cast post and core, Orthodontic extrusion, Sub-gingival fracture.

Conservative Dentistry and Endodontic Journal (2019): 10.5005/jp-journals-10048-0043

\section{INTRODUCTION}

Traumatic injuries to the teeth, especially in the esthetic region, pose a great challenge to a dentist. Children in the age group of 8-15 are commonly seen with dental traumatic injuries. When the fracture line is below the level of the gingiva, the prognosis of such a fractured tooth is considered questionable or hopeless. Maxillary anterior teeth are most often affected, and $80 \%$ of them are maxillary central incisors. With the recent trend and attitude toward dental implants, extraction remains the common treatment modality. However, it should be considered as the last option, and every attempt should be made to preserve and restore the natural tooth structure. Such treatment modalities involve a multidisciplinary approach including endodontics, periodontal crown lengthening, and or orthodontic extrusion followed by prosthetic rehabilitation. ${ }^{1}$ Periodontal crown lengthening involves the removal of the supporting crestal alveolar bone, while orthodontic intervention forcibly extrudes the tooth. Both attempt to expose sufficient coronal tooth structure for proper prosthetic restoration. Crown lengthening procedures may expose excess of root and, in turn, may compromise esthetic results that can be avoided by the use of orthodontic extrusion. ${ }^{2}$ Tooth extrusion by orthodontic procedures was more conservative, cost effective, and allow retention of the tooth without a need of a fixed bridge. This case report presents a multidisciplinary approach to a traumatized tooth including endodontic treatment, orthodontic extrusion, and post-core-crown procedure to restore a right maxillary central incisor to achieve a satisfactory cosmetic result.

\section{Case Description}

A 27-year-old male patient was referred immediately at the Department of Conservative Dentistry and Endodontics with the

\footnotetext{
${ }^{1-5}$ Department of Conservative Dentistry and Endodontics, Azeezia College of Dental Sciences and Research, Kollam, Kerala, India

Corresponding Author: Emi George, Department of Conservative Dentistry and Endodontics, Azeezia College of Dental Sciences and Research, Kollam, Kerala, India, Phone: +91 9605033594, e-mail: emigeorge92@gmail.com
}

How to cite this article: George E, Nair KR, et al. Multidisciplinary Management of Anterior Traumatized Tooth: A Case Report. Cons Dent Endod J 2019;4(1):18-20.

Source of support: Nil

Conflict of interest: None

fractured upper right central incisor following a sharp spanner hit onto a single tooth. Clinical examination showed a horizontal and oblique fracture in the labial aspect of 11 and, palatally, it was extending subgingivally (Fig. 1). On vitality testing, all adjacent teeth give a normal response. On radiographic examination, it revealed multiple fracture line extending horizontally (Fig. 2). Multiple fractured fragments were attached to the soft tissue and the fracture line was extending below the gingiva and bleeding was present. The case was diagnosed as a complicated crown-root fracture. It was decided to remove the fragment before the endodontic treatment. The fragment was gently removed under local anesthesia and the fracture line was extending $1.5 \mathrm{~mm}$ below the cervical area. The exposed pulp tissue was removed immediately and root canal treatment was completed in two visits. Orthodontic extrusion was planned subsequently. After the tooth was asymptomatic for a week, orthodontic extrusion was carried out (Fig. 3). Brackets were placed in the 11. Extrusion was done using a double-elastic band. Based on the depth of the palatal fracture line, it was planned to extrude the tooth to about

(O) The Author(s). 20190pen Access This article is distributed under the terms of the Creative Commons Attribution 4.0 International License (https://creativecommons. org/licenses/by-nc/4.0/), which permits unrestricted use, distribution, and non-commercial reproduction in any medium, provided you give appropriate credit to the original author(s) and the source, provide a link to the Creative Commons license, and indicate if changes were made. The Creative Commons Public Domain Dedication waiver (http://creativecommons.org/publicdomain/zero/1.0/) applies to the data made available in this article, unless otherwise stated. 


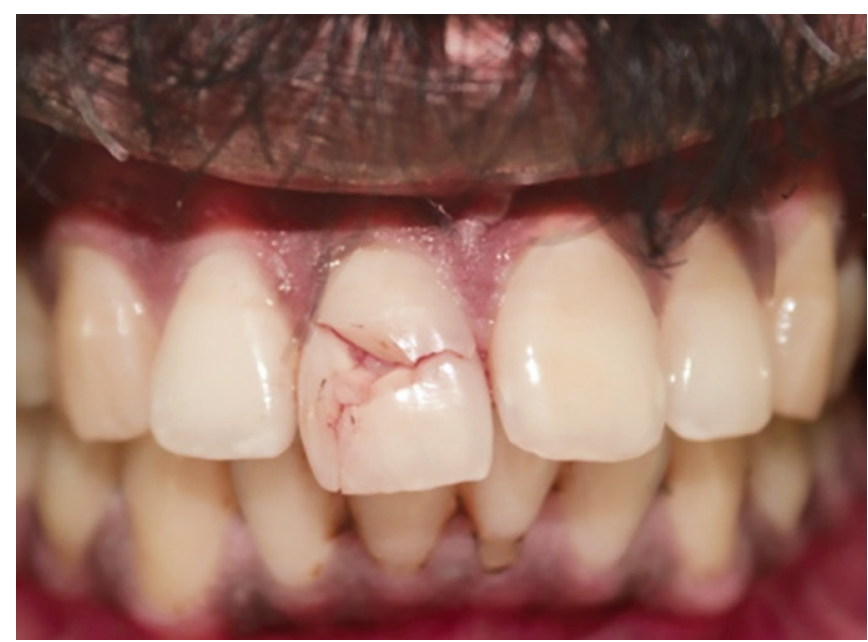

Fig. 1: Preoperative image

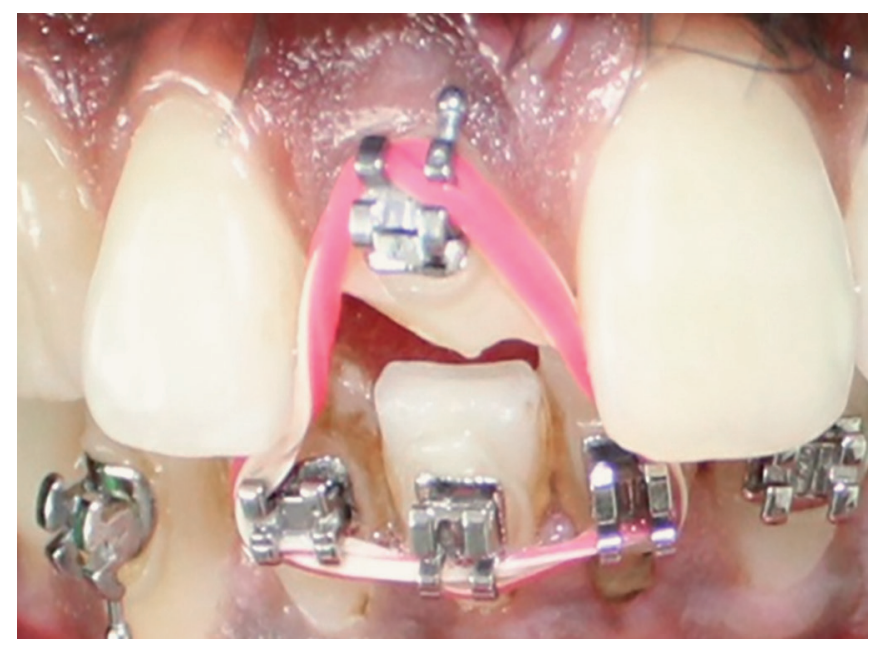

Fig. 3: Orthodontic extrusion

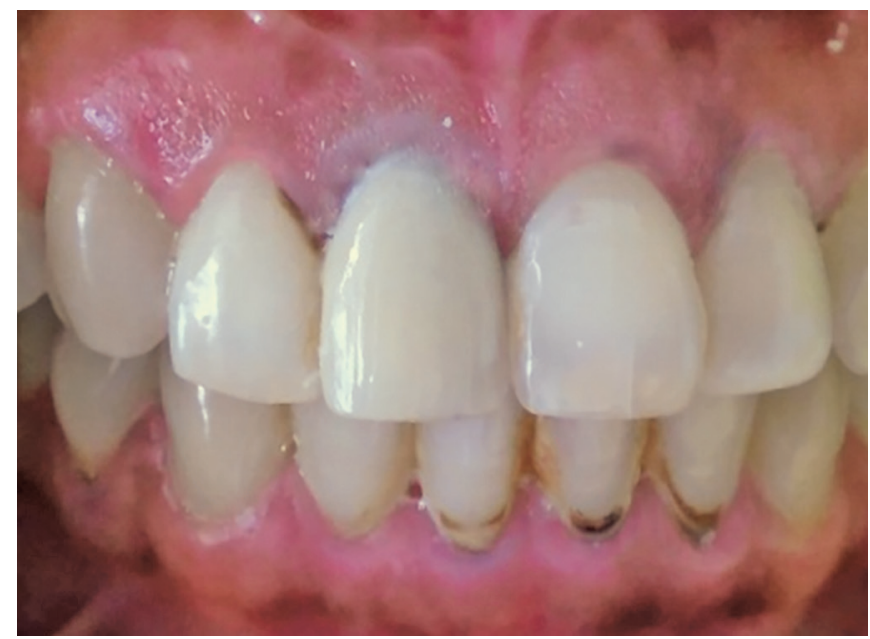

Fig. 5: Metal ceramic crown placement

1-2 mm. The elastic module and band was changed every 1 week until the desired extrusion was achieved. After 8 weeks, the tooth had extruded around $2 \mathrm{~mm}$ of palatal tooth structure sufficient to provide a ferrule of $1 \mathrm{~mm}$ (Fig. 4). At this point, the remaining coronal structure was assessed, and it was judged to be adequate to retain a

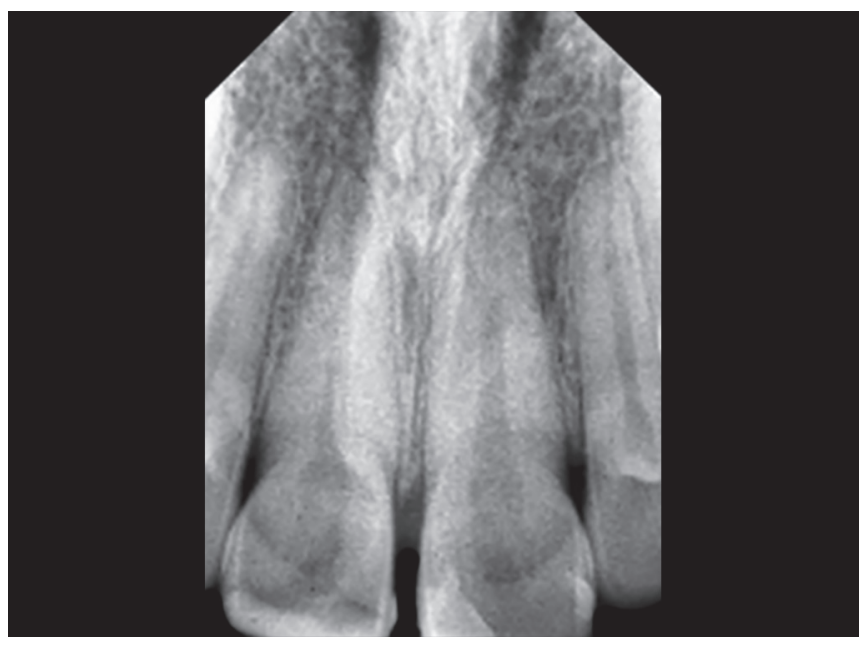

Fig. 2: Preoperative IOPA

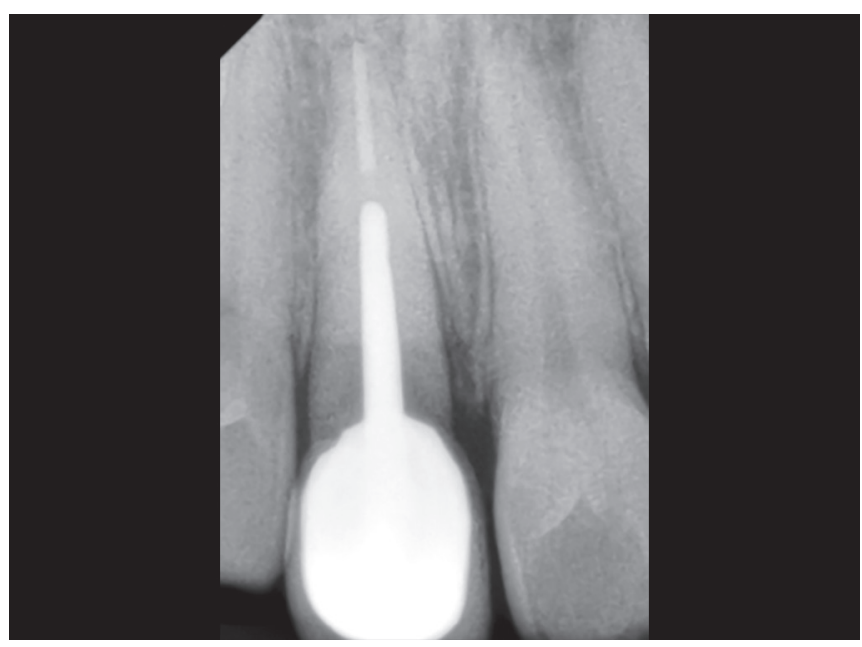

Fig. 4: Postoperative radiograph

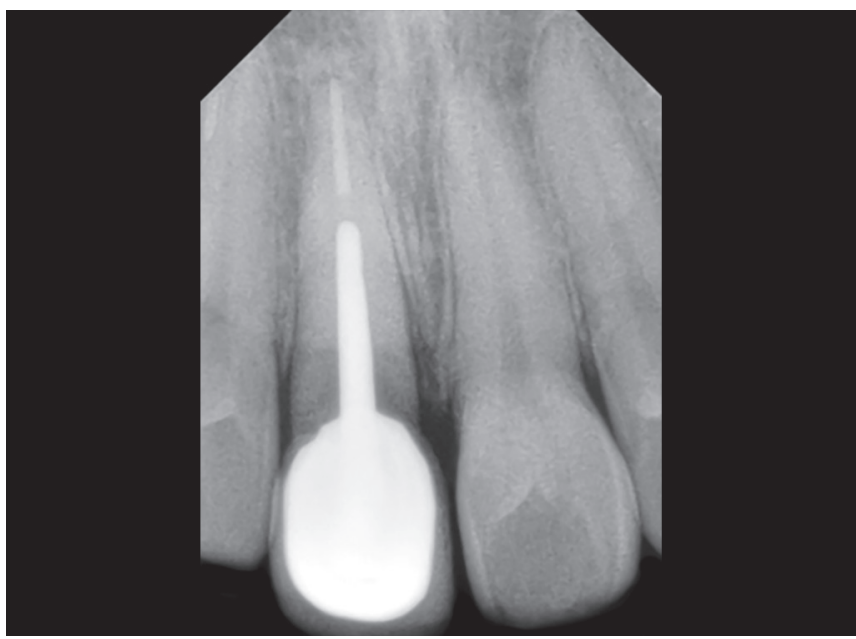

Fig. 6: One-year follow up

definitive full coverage restoration (Fig. 5). The tooth was stabilized for 8 weeks prior for the fabrication of cast post and core. A cast post and core was prepared, and a definitive metal-ceramic crown was placed over 11. The patient was reviewed for 6 months and 1 year (Fig. 6). The treatment outcome was stable and symptomless. 


\section{Discussion}

The location of the fracture line affects the treatment options, clinical outcomes, and prognosis of teeth. Those fractured in the subgingival area have been found to be the bleakest because of the loss of the coronal fragment stability and pulpal vitality. ${ }^{3}$ Root canal therapy is advised for those teeth in which pulp neurovascular supply is disrupted, to avoid pulp necrosis that can lead to external inflammatory root resorption. The 3-4 $\mathrm{mm}$ distance from the alveolar crest to the coronal extension of the remaining tooth structure has been recommended for optimal periodontal health. In this case, remaining tooth structure is inadequate to obtain ferrule without involving the biologic width. ${ }^{4}$ There are various treatment options of tooth fracture involving the biologic width: root extrusion technique, crown lengthening procedures, and combination of both. Orthodontic extrusion is recommended when existing clinical crown height cannot permit the placement of a crown ferrule. ${ }^{5}$

Orthodontic extrusion is a treatment choice for tooth fractures, especially where aesthetic considerations are involved. It provides benefits for the patient as opposed to surgical crown lengthening. The most important advantage is that there is no bone loss as opposed to the techniques of surgical crown lengthening. If the fracture line is positioned both below the alveolar bone and gingival free margin, and the length of the root segment is sufficient enough to support a coronal restoration, then the root can be endodontically treated and, afterward, orthodontically extruded to elevate the fracture plane above the gingival margin. These procedures enable more favorable prosthodontic coronal restoration by securing its good sealing and esthetics, and, moreover, preserving a good periodontal tissue health. Various splints and appliances have been proposed for an orthodontic-forced eruption. Rapid extrusion is accompanied with some problems; higher forces exerted on the tooth may lead to pulpal necrosis and root resorption. However, pulpal death is not a concern for endodontically treated tooth, and studies have indicated that root resorption after extrusion is rare. But in this case report, a slow orthodontic extrusion technique is used to obtain a good amount of hard and soft tissue. But this technique requires more time.

Ulusoy et al. ${ }^{6}$ and Fidel et al. ${ }^{7}$ described a technique for extrusion using bonded brackets on the adjacent teeth. Simon et al. $^{8}$ indicated that the orthodontic extrusion should become a routine procedure in dentistry. They also stressed that the orthodontically extruded tooth must be stabilized for 8-12 weeks prior to fabrication of a permanent post and core. They also found that 8-12 weeks of stabilization of orthodontically extruded teeth a have better prognosis. In this case, the tooth was stabilized for 8 weeks prior to the fabrication of cast post and core.

When the remaining tooth structure is less than $50 \%$, cast post and core is recommended for the retention of the crown because of its superior adaptation to the root canal, long-term prognosis, and high strength. ${ }^{9}$ It has been reported that the presence of a 2-mm crown ferrule surrounding remaining tooth structure enhanced fracture resistance, which was restored with cast post and core and metal-ceramic crown. According to Gómez-Polo et al., ${ }^{10}$ cast metal post has shown higher survival rates over 10 years. The patient was reviewed after 3 months, 6 months, and 1 year. Clinical and radiographic outcomes were satisfactory.

\section{Conclusion}

Management of fracture extending subgingivally has various treatment options. Gingivectomy of the affected tooth can change the gingival contour of the tooth. Orthodontic extrusion is a conservative procedure that allows extrusion of a tooth without any bone loss. An extrusion of $2 \mathrm{~mm}$ was sufficient to fabricate a restoration. Cast post and core can adapt to the canal and strengthen the tooth. It can be considered as a conservative treatment option for retaining natural tooth and for the health of supporting tissues.

\section{Clinical Significance}

Traumatic injuries to the teeth in the esthetic region of the face pose a great challenge to the dentist. Orthodontic extrusion of the teeth is a conservative procedure and can be considered as a choice when treating a patient with coronal fractures of the anterior teeth especially in a young patient.

\section{References}

1. Mittal R, Gupta S. Managing sub-gingival fracture by multidisciplinary approach: endodontics-forced orthodontic extrusion and prosthetic rehabilitation. Saudi Endod J 2013;3:2.

2. Fournier A. Orthodontic management of subgingivally fractured teeth. J Clin Orthod 1981;15:502-503.

3. Welbury R, Kinirons MJ, et al. Outcomes for root-fractured permanent incisors: a retrospective study. Pediatr Dent 2002;24:98-102.

4. Potashnick SR, Rosenberg ES. Forced eruption: principles in periodontics and restorative dentistry. J Prosthet Dent 1982;48: 141-148. DOI: 10.1016/0022-3913(82)90100-7.

5. Johnson RH. Lengthening clinical crowns. J Am Dent Assoc 1990;121:473-476. DOI: 10.14219/jada.archive.1990.0207.

6. Ulusoy AT, Tunc ES, et al. Multidisciplinary treatment of a subgingivally fractured tooth with indirect composite restoration: a case report. J Dent Child 2012;79(2):79-83.

7. Fidel SR, Fidel-Junior RA, et al. Clinical management of a complicated crown-root fracture: a case report. Braz Dent J 2011;22:258-262.

8. Simon $\mathrm{JH}$, Lythgoe JB, et al. Clinical and histologic evaluation of extruded endodontically treated teeth in dogs. Oral Surg Oral Med Oral Pathol 1980;50:361-371. DOI: 10.1016/0030-4220(80)90422-3.

9. Ivey DW, Calhoun RL, et al. Orthodontic extrusion: its use in restorative dentistry. J Prosthet Dent 1980;43:401-407. DOI: 10.1016/00223913(80)90209-7.

10. Gómez-Polo $\mathrm{M}$, Llidó $\mathrm{B}$, et al. A 10 year retrospective study of the survival rate of teeth restored with metal prefabricated posts vs cast metal posts and core. J Dent 2010;38(11):916-920. DOI: 10.1016/ j.jdent.2010.08.006. 